\title{
Investigation of Polymer-70\% Aluminum Powder Composite
}

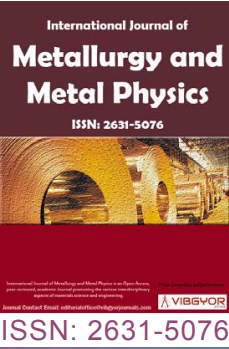

\section{A Lotfy' ${ }^{1 *}$ E Mohamed ${ }^{1}, A K$ Handam $^{2}$ and Barkov $R$ Yu $^{3}$}

${ }^{1}$ Central Metallurgical Research Institute (CMRDI), Cairo, Egypt

${ }^{2}$ Department of Renewable Energy, Jadara University, Jordan

${ }^{3}$ NUST "MISiS", Leninskiy Ave. 4, 119049, Russia

\begin{abstract}
Metals and polymers permutation in order to produce polymer metals composites attain new fascination and significance to several authors. The first effort to syndicate these two classes of materials was formulated in the earlier years of the $20^{\text {th }}$ era. In this article aluminum flakes were positively assimilated in polyethylene PE matrix to syndicate the valuable properties of metals and polymers. They extend to light weight, endurance to corrosion, brisk fabrication rates and a extensive range of moduli etc. In the current research, differing from $0 \%$ to $70 \%$ by volume of aluminum flakes were assimilated into polyethylene (PE) matrix by means of mechanical stirring. The impact of filler particle addition on the properties of the composites was identified.
\end{abstract}

\section{Keywords}

Composites, Polymers, Flakes

\section{Introduction}

As Composite materials acquire variety of unusual properties; therefore, several types of composite largely used in various industrial fields, for instance automotive, electrical and electronic, aerospace and machine building industries [1-3]. In the past few years various researchers give enormous consideration to likely hoods of use of polymers comprising dispersed conductive fillers, as well as fabrication techniques where polymer metal composites can be prepared [4-8].

In the scope of electrical applications, insulating type of polymer materials poses many pivotal advantages. In every occasion when electrical currents applications needed, polymer materials present ideal contenders in which insulation of high voltages are essential.

Conversely, in some applications wherever polymers deem to be part of absolute equipment which necessitate static accumulation and electromagnetic shielding these gains may become significant disadvantages. Accordingly, forming polymers appropriately conductive is essential to some electrical applications [9-11].

Fabricating composites by integrating powder metals in polymer matrix, would give the permu-

*Corresponding author: A Lotfy, Central Metallurgical Research Institute (CMRDI), PO Box 87, Helwan, Cairo, Egypt

Accepted: March 29, 2020; Published: March 31, 2020

Copyright: (c) 2020 Lotfy A, et al. This is an open-access article distributed under the terms of the Creative Commons Attribution License, which permits unrestricted use, distribution, and reproduction in any medium, provided the original author and source are credited.

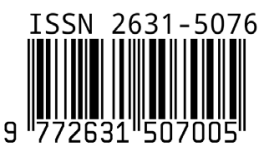

Lotfy et al. Int J Metall Met Phys 2020, 5:051 
tations of two constituents metal and polymer to the absolute product. Their properties are appropriate to situations where the release of static electricity, heat conduction, electromagnetic intrusion shields, galvanothermy and changings are the emphasis of consideration [12-15].

These polymer metal composite materials propose lot of gains such as affluence in fabrication, low cost and corrosion resistance facilitate to serve as most conceding materials serving the industrial usage, also the conductivity level can be 'fixed' to fulfill the requirements of the end user.

It's workable to make nonconductive polymer materials conductive by accumulation of various conductive filler metals such as gold, silver, nickel, indium and copper, and carbon black or graphite powder $[16,17]$. Polymers material can be designed with precise properties customize to every application by considering additives of filler metals. Since electrical conductivity point of view, $10^{-2} \mathrm{~S} /$ $\mathrm{cm}$ (electrical conductivity) and upper reflect for shielding applications, $10^{-8}$ to $10^{-2} \mathrm{~S} / \mathrm{cm}$ for relatively conductive appliance while, in the range of 10 12 to $10^{-8}$ Siemens/cm $(\mathrm{S} / \mathrm{cm})$ for electrostatic discharge (ESD) applications [18].

Numerous factors controlling the functioning of conductive polymer metal composites for instance volume, type and conductivity of filler metals enhanced and the selected polymer matrix as well. Polymer metal composites has been studied by many researchers [19-22], these factors are all interconnected and consequently essentially be addressed collectively to yield the most cost-effective material selection and meet the application requirements.

\section{Materials and Methods}

\section{Materials}

The polymer used in this research was solvent free epoxy primer TIAL P (A) manufactured by IFC Techprocomplect LLC Russian federation, with viscous homogenous black color. Aluminium flakes was provided by MISIS powder metallurgy laboratory with average size of 70-100 $\mu \mathrm{m}$ and 99.5 metal purity.

\section{Sample preparation}

Polymer with aluminium metal flakes were mixed together to produce polymer matrix composites by means of mechanical stirring. Using mechanical

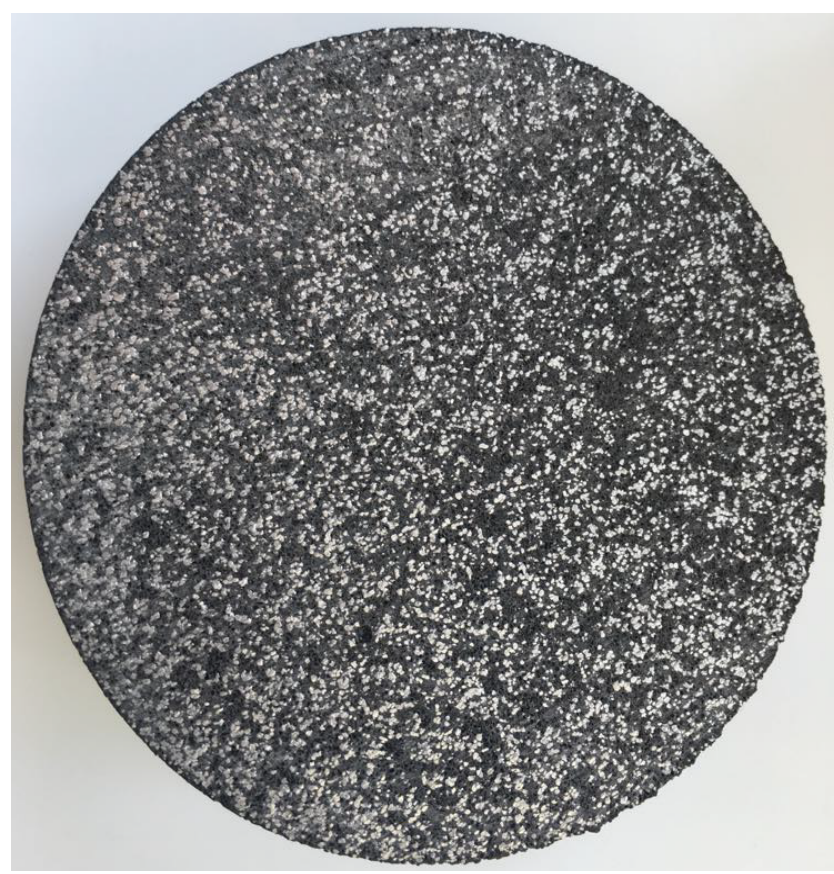

Figure 1: Optical micrograph of polymer $-70 \%$ aluminium composites.

motor speed of $40 \mathrm{rpm}, 70 \%$ of aluminium powder were incorporated inside polymer matrix, the internal mixer machine consists of mixing chamber having two counter-rotating rotors and the time of stirring was 15 min after mechanical stirring the composites was left more than $4 \mathrm{hrs}$. for curing and stabilizing. The composite sample were mechanically cut into appropriate dimension for subsequent testing.

\section{Results and Discussion}

\section{Microstructure}

In order to measure and evaluate the microstructure of polymer aluminum composite the sample was horizontally cut to make analyzing for the cross section. As shown in Figure 1 and Figure 2 the aluminum flakes were seen clearly along the surface of the polymer in white color while the polymer appears in a black color. Also, the figure shows the normal distribution of the flakes along with some voids between the two constituents.

\section{Density and electrical conductivity}

Observing the aluminum flakes clearly as in Figure 1 and Figure 2 shows the dominance of aluminum through the composites, which increases the electrical conductivity. As aluminum is a proper electrical conductor, hence adding it to the polymer will have a great effect on the properties, how- 


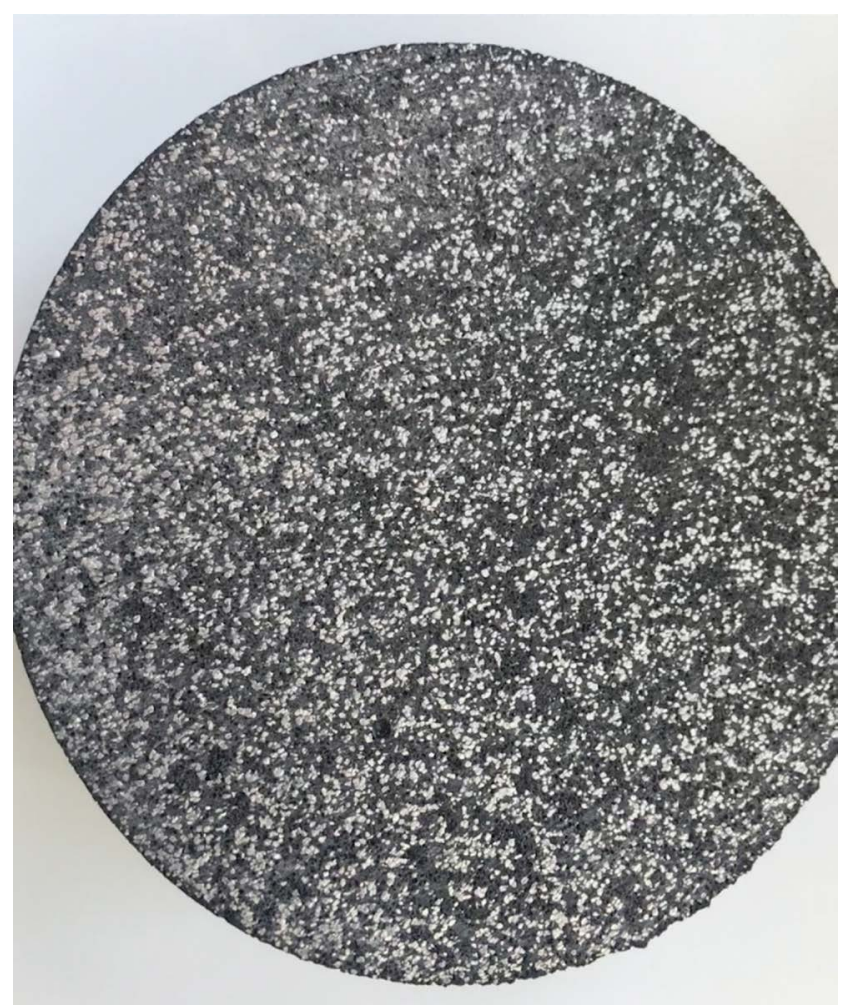

Figure 2: Optical micrograph of polymer -70\% aluminium composites (more magnification).

ever, all theses properties will be greatly affected by density. The theoretical density for this composite was calculating using Rule of Mixture equation:

$$
\rho_{\text {theory }}=\rho_{\mathrm{f}} \mathrm{V}_{\mathrm{f}}+\rho_{\mathrm{m}} \mathrm{V}_{\mathrm{m}}
$$

Where $\rho=$ Density, $V_{m}=$ Matrix volume fraction and $V_{f}=$ Filler volume fraction

The theoretical density of the composites was calculated by the above equation and recorded:

\section{$2.7 \times 70+1.2 \times 30=225 \mathrm{gm} / \mathrm{cm}^{3}$}

However, without adding flakes was recorded $120 \mathrm{gm} / \mathrm{cm}^{3}$

This means aluminum flakes has increased the density of the composites which makes the compound more suitable for use in many devices. Porosity and density one of the major factors controlling the polymer metal composites behavior. Moreover, porosity may affect the electrical conductivity of the produced composites. As, large amount of porosity would prevent the formation of a continuous metal-to-metal network, decreasing the conductivity.

\section{Conclusions}

1. The polymer - $70 \%$ aluminum composites were scornfully produced by means of mechanical stirring.

2. The microstructure photos show good distribution of aluminum flakes along the polymer matrix.

3. In the optical photos of composites cross section, it has shown clearly the formation of voids.

4. Theoretical density of the composites was increased twice density of the polymer by adding 70\% Aluminum flakes.

\section{References}

1. DK Rajak, DD Pagar, R Kumar, Cl Pruncu (2019) Recent progress of reinforcement materials: A comprehensive overview of composite materials. Journal of Materials Research and Technology 8: 6354-6374.

2. E Baur, TA Osswald, N Rudolph (2019) Material properties and testing methods. ( $5^{\text {th }}$ edn), Plastics Handbook, 45-175.

3. J Chen, X Gao (2019) Directional dependence of electrical and thermal properties in graphene-nanoplatelet-based composite materials. Results in Physics 15: 102608.

4. S Doagou-Rad, A Islam, S Antusch, J Jung, A Klein, et al. (2019) Investigation of conductive hybrid polymer composites reinforced with copper micro fibers and carbon nanotubes produced by injection molding. Materials Today Communications 20: 100566.

5. W Ji, H Deng, C Sun, Q Fu (2019) Nickel hydroxide as novel filler for high energy density dielectric polymer composites. Composites Science and Technology 172: 117-124.

6. Y Kazemi, AR Kakroodi, LH Mark, T Filleter, CB Park (2019) Effects of polymer-filler interactions on controlling the conductive network formation in polyamide 6/multi-Walled carbon nanotube composites. Polymer 178: 121684.

7. P Karami, SS Khasraghi, Mj Hashemi, S Rabiei, A Shojaei (2019) Polymer/nanodiamond composites - a comprehensive review from synthesis and fabrication to properties and applications. Advances in Colloid and Interface Science 269: 122-151.

8. W Peng, Y Zhang, J Gao, Y Wang, Y Chen, et al. (2019) Fabrication and performance of ionic polymer-metal composites for biomimetic applications. Sensors and Actuators A: Physical 299: 111613.

9. C Ning, Z Zhou, G Tan, Y Zhu, C Mao (2018) Electroactive polymers for tissue regeneration: Developments and perspectives. Progress in Polymer Science 81: 144-162. 
10.H Yuan, Y Wang, T Li, P Ma, S Zhang, et al. (2018) Highly thermal conductive and electrically insulating polymer composites based on polydopamine-coated copper nanowire. Composites Science and Technology 164: 153-159.

11.A Gabe, MJ Mostazo-López, D Salinas-Torres, E Morallón, D Cazorla-Amorós (2017) Synthesis of conducting polymer/carbon material composites and their application in electrical energy storage. Hybrid Polymer Composite Materials 8: 173-209.

12.A Mansour, F Poncin-Epaillard, D Debarnot (2019) Distribution of metal nanoparticles in a plasma polymer matrix according to the structure of the polymer and the nature of the metal. Thin Solid Films 699: 137261.

13. H Che, X Chu, P Vo, S Yue (2017) Cold spray of mixed metal powders on carbon fibre reinforced polymers. Surface and Coatings Technology 329: 232-243.

14.CA Chatham, TE Long, CB Williams (2019) A review of the process physics and material screening methods for polymer powder bed fusion additive manufacturing. Progress in Polymer Science 93: 68-95.

15.S Yuan, F Shen, CK Chua, K Zhou (2019) Polymeric composites for powder-based additive manufacturing: Materials and applications. Progress in Polymer Science 91: 141-168.

16.S Belhousse, FZ Tighilt, S Sam, K Lasmi, K Hamdani, et al. (2017) Functionalization of silicon nanowires by conductive and non-conductive polymers. Applied Surface Science 421: 134-141.

17.SJ Kim, C Hong, KS Jang (2019) Theoretical analysis and development of thermally conductive polymer composites. Polymer 176: 110-117.

18.SN Karri, P Srinivasan (2019) Synthesis of PEDOT:PSS using benzoyl peroxide as an alternative oxidizing agent for ESD coating and electro-active material in supercapacitor. Materials Science for Energy Technologies 2: 208-215.

19.X Meng, Y Huang, Y Xie, J Li, M Guan, et al. (2019) Friction self-riveting welding between polymer matrix composites and metals. Composites Part A: Applied Science and Manufacturing 127: 105624.

20.C Sorini, A Chattopadhyay, RK Goldberg (2019) Micromechanical modeling of the effects of adiabatic heating on the high strain rate deformation of polymer matrix composites. Composite Structures 215: 377-384.

21.D Karimi, AS Milani (2019) SRVE modeling of particulate polymer matrix composites with irregularly shaped inclusions: Application to a green stone composite. Composite Structures 228: 111331.

22.D Quade, S Jana, L McCorkle (2019) The influence of thin film adhesives in pullout tests between nickeltitanium shape memory alloy and carbon fiber reinforced polymer matrix composites. Composites Part B: Engineering 176: 107321. 